\title{
The prevalence of livestock diseases in the South Pacific
}

\author{
Kristina Naden ${ }^{1}$
}

Received: 13 April 2020 / Accepted: 20 May 2020 / Published online: 26 May 2020

(C) Springer Nature B.V. 2020

Bakare et al. (2020) provide a critical link between the wellestablished field of traditional medicine use in the South Pacific Island Countries (SPICs) and the paucity of ethnoveterinary medicine application in animal husbandry. Wild animals are known to self-medicate (Huffman \& Caton, 2001), and leveraging the traditional medicines used to treat humans as therapeutics for treating domesticated animals is a promising therapeutic approach. The prioritized list of livestock diseases provided by the authors is a welcomed starting point for this approach; yet, surprisingly, there are yet to be any broad surveys to determine the prevalence of these diseases throughout the Pacific.

The true level of infectious animal diseases in SPICs is unknown, primarily due to a lack of veterinary healthcare available, including diagnostic services. Clinical reports have identified a range of primarily zoonotic diseases (Brioudes et al., 2015), with leptospirosis being the most prevalent in SPICs (Costa et al., 2015; Guernier et al., 2018). In SPICs, it is common for people to live in close proximity to animals thereby increasing the risk of zoonotic transmission, thus making the prevalence of animal diseases a One Health issue (Shapiro et al., 2017) as understanding the prevalence of livestock infections can simultaneously improve both animal and public health. Importantly, there is an established link between the management of zoonotic diseases and improved human health (Zinsstag et al., 2007).

The first step to improving animal health in SPICs is to determine the prevalence of the most common livestock diseases through a broad survey of domestic and, potentially, feral animals. The framework for this type of survey has been established through the Food Animal Biosecurity Network (FABN), founded in 2010 between Fiji, Papua New Guinea, Vanuatu, and Solomon Islands, and funded by the Australian

Kristina Naden

knaden@unitec.ac.nz

1 School of Environmental and Animal Sciences, Unitec Institute of Technology, Private Bag 92025, Victoria Street West, Auckland 1142, New Zealand
Government. Combined, member countries represent $90 \%$ of human inhabitants of SPICs. The purpose of the FABN is to provide and improve field and laboratory capabilities in SPICs, with a focus on surveillance (Brioudes et al., 2015), by providing training at regional and national levels. For example, the FABN was utilized to co-ordinate surveillance and reporting of the zoonotic disease brucellosis, and identified a clear re-emergence of the disease in FABN member countries (Tukana, 2018). Unfortunately, funding for the FABN was rescinded in 2013.

Using frameworks such as the FABN for data collection would require a multi-agency approach, with both human and animal medical experts involved. Prior to initiating such a complex undertaking, performing a pilot survey to solidify logistics, highlight challenges, and hone the research approach is essential. Specifically, this proposed study would involve using point-of-care assessment (such as a SNAP or WITNESS test) to determine the prevalence of parvovirus and leptospirosis; furthermore, simultaneously, serum from each individual should be collected, blotted on filter paper, and dried to allow subsequent PCR-based assessment for other diseases.

The spread of SARS-COV-2 and associated disease COVID-19 has highlighted the importance of understanding the prevalence of zoonotic diseases. In places where people are in close proximity to animals, such as SPICs, the first step in identifying and treating animal diseases is to understand the prevalence of these diseases in animals.

\section{References}

Bakare, A. G., Shah, S., Bautista-Jimenez, V., Bhat, J. A., Dayal, S. R., \& Madzimure, J. (2020). Potential of ethno-veterinary medicine in animal health care practices in the South Pacific Island countries: a review. Tropical Animal Health and Production, (Harrington 2001). https://doi.org/10.1007/s11250-019-02192-7

Brioudes, A., Warner, J., Hedlefs, R., \& Gummow, B. (2015). Diseases of livestock in the Pacific Islands region: Setting priorities for food animal biosecurity. Acta Tropica, 143, 66-76. https://doi.org/10. 1016/j.actatropica.2014.12.012

Costa, F., Hagan, J. E., Calcagno, J., Kane, M., Torgerson, P., MartinezSilveira, M. S., ... Ko, A. I. (2015). Global morbidity and mortality 
of leptospirosis: A systematic review. PLOS Neglected Tropical Diseases, 9(9), 1-19. https://doi.org/10.1371/journal.pntd.0003898

Guernier, V., Goarant, C., Benschop, J., \& Lau, C. L. (2018). A systematic review of human and animal leptospirosis in the Pacific Islands reveals pathogen and reservoir diversity. PLOS Neglected Tropical Diseases, 12(5), e0006503. https://doi.org/10.1371/journal.pntd. 0006503

Huffman, M. A., \& Caton, J. M. (2001). Self-induced increase of gut motility and the control of parasitic infections in wild chimpanzees. International Journal of Primatology, 22(3), 329-346.

Shapiro, A. J., Brown, G., Norris, J. M., Bosward, K. L., Marriot, D. J., Balakrishnan, N., ... Malik, R. (2017). Vector-borne and zoonotic diseases of dogs in north-west New South Wales and the Northern
Territory, Australia. BMC Veterinary Research, 13(1), 238. https:// doi.org/10.1186/s12917-017-1169-2

Tukana, A. (2018). A study of Brucellosis in cattle within the Pacific Island Community as a model for disease surveillance and reporting. James Cook University.

Zinsstag, J., Schelling, E., Roth, F., Bonfoh, B., De Savigny, D., \& Tanner, M. (2007). Human benefits of animal interventions for zoonosis control. Emerging Infectious Diseases, 13(4), 527-531. Retrieved from https://wwwnc.cdc.gov/eid/article/13/4/06-0381_article.

Publisher's note Springer Nature remains neutral with regard to jurisdictional claims in published maps and institutional affiliations. 